\title{
Las narraciones de la cuarentena durante la crisis de la COVID-19 a través de la música: emociones y actividades compartidas por Stay Homas
}

\author{
Priscila Alvarez-Cueva \\ Universitat Pompeu Fabra \\ priscila.alvarez@upf.edu \\ https://orcid.org/0000-0002-7570-6548
}

\author{
Maria-Jose Masanet \\ Universitat de Barcelona \\ mjose.masanet@ub.edu \\ https://orcid.org/0000-0002-1217-9840
}

\author{
Ana Belén Cano-Hila \\ Universitat de Barcelona \\ anabelencano@ub.edu \\ https://orcid.org/0000-0003-3145-9466
}

\section{The narratives of the quarantine during the COVID-19 crisis through music: shared emotions and activities by Stay Homas}

\begin{abstract}
RESUMEN
"Desconfinamiento" es el título del mix tape de cinco canciones del trío catalán Stay Homas, quienes han sido catalogados como la revelación del confinamiento. El presente estudio concibe estas canciones como narraciones personales. A través de un análisis cualitativo de texto (Krippendorff, 2004), el estudio presenta cinco categorías de elementos que relatan una realidad social vivida dentro

del tiempo de cuarentena en Barcelona. Las categorías que el estudio presenta recogen: a) deseos, b) emociones,

c) personas, d) prácticas y e) reflexiones, en tiempos de confinamiento. El estudio sostiene que las características descritas en el análisis conectan con las emociones y generan respuestas de interés, empatía y solidaridad más allá

de las variantes de la edad, el género y la locación. Las canciones de Stay Homas funcionan como un "antídoto" que

suaviza la complejidad de los tiempos que vivimos y sus posibles consecuencias. Finalmente, el estudio discute algunas oportunidades para futuras investigaciones, destacando dos consideraciones: mirar la música como una oportunidad

para identificar elementos clave en el acompañamiento emocional, y considerarla como una herramienta que contribuye en el bienestar social.
\end{abstract}

PALABRAS CLAVE

Música; Análisis cualitativo; Bienestar social; Confinamiento; COVID-19; Stay Homas.
ABSTRACT

"Desconfinamiento" is the title of the mix tape of five songs by the Catalan trio Stay Homas, who have been classified as the revelation of confinement. The present study conceives these songs as personal narratives. Through a qualitative text analysis (Krippendorff, 2004), the study presents five categories of elements that relate to a social reality lived within the time of quarantine in Barcelona. The categories that the study presents include $a$ ) wishes, $b$ ) emotions, c) people, d) practices and e) reflections, in times of confinement. The study argues that the characteristics described in the analysis connect with emotions and generate responses of interest, empathy, and solidarity beyond the variants of age, gender, and location. Stay Homas songs work as an "antidote" that softens the complexity of the times we live in and its possible consequences. Finally, the study discusses some opportunities for future research, highlighting two considerations: looking at music as an opportunity to identify key elements in emotional accompaniment, and considering it as a tool that contributes to social well-being.

KEYWORDS

Music; Qualitative analysis; Social welfare; Lockdown; COVID-19; Stay Homas. 


\section{Introducción}

El confinamiento, a partir de la crisis de la COVID-19, supuso un cambio importante en el modo de vida de millares de personas alrededor del mundo (Gómez Gerez et al., 2020). En marzo del 2020, las fotografías independientes y de los medios de comunicación ponían en evidencia desolación en las calles italianas y españolas, una realidad de la que se hacían eco cada vez más países, en todos los continentes. Sentimientos de miedo e inquietud se agolpaban en las plataformas digitales mientras los gobiernos de todo el mundo trataban de "contener" la pandemia. En medio de la ansiedad generada por esta situación y la creciente necesidad de desconectar-por un momento- del miedo, el sufrimiento y la angustia, cientos de personas encontraron un espacio catalizador dentro del arte, particularmente en la música, en un intento de conseguir algún tipo de conexión social que reforzara los sentimientos de compañía, apoyo y solidaridad.

Muchos artistas, en todas las latitudes, mudaron sus escenarios a un formato digital, haciendo uso de plataformas como YouTube, Instagram, Twitter y Facebook, entre otras (Zhao, Chen y Zhao, 2020). Desde Neil Diamond, con su adaptación de "Sweet Caroline", para concienciar sobre el lavado de manos (Lehman, 2020), pasando por los conciertos online gratuitos de varios músicos, como es el caso del español Alejandro Sanz con \#LaGiraSeQuedaEnCasa ${ }^{1}$ o el colombiano Andrés Cepeda con \#ConciertoEnTuCasa ${ }^{2}$, hasta la iniciativa de varios artistas ecuatorianos, encabezados por el rapero AU-D con \#MusicaDesdeCaleta, que consistió en una publicación frecuente de varios videos colaborativos entre artistas, mientras interpretan sus temas más conocidos desde sus propios hogares. Todas estas iniciativas compartieron un mensaje en común: el de quedarse en casa, alineado con el momento y las medidas que se tomaban para frenar el número de contagios de la enfermedad.

En España, la canción "Los abrazos prohibidos" de Vetusta Morla (Santos, Bac y Elorrieta, 2020), marcó un momento importante al unir a varias voces conocidas para cantar en apoyo a la sanidad pública, con el objetivo adicional de que todo lo recaudado por la canción se destinara al Consejo Superior de Investigaciones Científicas (CSIC) para contribuir en la investigación sobre el coronavirus (Santos et al., 2020).

Como se puede observar, los artistas encontraron en las redes sociales una manera de acompañar a las personas y expresar sus emociones en tiempos complejos e inciertos. Durante la crisis, las grabaciones o videos en directo se convirtieron en "escenarios virtuales, en la forma de unir a la gente y compartir la pasión por la música, (en) una manera de adaptarse a una realidad cambiante y de incorporar formas de comunicación con herramientas actuales." (Hernández y Pedraza, 2020, p. 164). Es en este sentido que la música emerge como una herramienta para reforzar los vínculos sociales en medio del escenario de incertidumbre (Partida Valdivia, 2020). De acuerdo con Partida Valdivia, "el afrontamiento de la contingencia por parte de músicos intérpretes y compositores, ha supuesto establecer relaciones sociales particulares en las que aparentemente se busca generar un clima de empatía y apoyo, ante la atmósfera de incertidumbre que la pandemia impone" (2020: 4).

Sin embargo, estas consideraciones no se han restringido únicamente a la música comercial. El contexto de crisis ha facilitado la participación de otros artistas cuyo impacto, en situaciones de "normalidad", no habría sido tan importante o no habría recibido tanto reconocimiento debido, justamente, a la dinámica de "la industria musical actual" (Illescas, 2015, p. 131). Este sería el caso del trío catalán Stay Homas, compuesto por Klaus Stroink, Guillem Boltó y Rai Benet, cuya conformación tiene lugar durante el confinamiento, por lo que su irrupción en la escena musical está demarcada por un contexto igualmente excepcional al de la crisis sanitaria en España.

A partir de sus interpretaciones -que se iniciaron en marzo de 2020-, transmitidas por medio de su cuenta de Instagram (@stay.homas) desde la terraza de su piso en la ciudad de Barcelona, Stay Homas se ha dado a conocer como "la revelación en el confinamiento" (Redacción, 2020), llegando a colocar algunos de sus temas dentro de la lista de las mejores canciones del año (Linés, 2020). Este trío ha pasado de improvisar temas musicales con una guitarra, un balde vacío y sus palmas, a conseguir que se agoten las entradas para su presentación en Barcelona -planificada para el 2021- en tan sólo quince minutos, además de lograr un contrato con Sony (Díaz, 2020).

A las características descritas se suman los más de 95.000 suscriptores en su canal de YouTube, más de 400.000 seguidores en Instagram y más de 38.000 seguidores en Twitter, lo que pone en evidencia el alcance que han tenido creando música en tiempos de confinamiento. Sin embargo, entre los datos más interesantes destaca que, de acuerdo con la entrevista realizada por Díaz (2020), antes de la crisis estos músicos tenía un grupo definido de seguidores -sobre todo jóvenes entre dieciocho y veinte y cinco años- y carecían de "la aprobación de una persona de más de cuarenta años" (Díaz, 2020). En cambio, de acuerdo con 
las estadísticas de Instagram que los artistas señalan en la entrevista, hoy en día cuentan con una audiencia que, mayoritariamente, supera los sesenta y cinco años.

Lo que evidencian estos datos es que, durante el confinamiento, Stay Homas ha sabido generar unas narraciones que han supuesto, de alguna manera, un apoyo y acompañamiento que la gente ha aplaudido y seguido con fidelidad. Es por ello que este trabajo toma como muestra de estudio el mix tape de Stay Homas, Desconfinamiento, que reúne los cinco temas más votados por sus seguidores (Stay Homas, 2020). El objetivo principal de este artículo es analizar las narraciones sobre el confinamiento, vehiculadas a través de la música, para entender qué acciones, emociones y/o situaciones se han destacado en la construcción de dichas narrativas. Para ello, se lleva a cabo un análisis cualitativo de texto (Krippendorff, 2004, p. 341) que, de manera inductiva, identifica qué elementos de la vida diaria y significados están presentes en las letras de las canciones del trío catalán, creadas durante la situación excepcional provocada por la crisis de la COVID-19, en España.

La hipótesis de partida de este estudio sostiene que las letras de las canciones producidas por Stay Homas relatan una realidad social vivida dentro de la crisis sanitaria en España que conecta, por un lado, con algunos de los hábitos, prácticas y emociones que se desprenden de la situación de confinamiento y, por el otro, con una audiencia que se homogeniza a partir de la identificación de una narrativa compartida que el trío presenta en sus letras, independientemente de variantes como la edad, el género, e incluso la localización física.

El texto se estructura a partir de un abordaje teórico sobre la música y su papel dentro de la crisis de la COVID-19, donde se enfatiza su importancia como un recurso generador de bienestar, tanto a nivel individual como a nivel social. A continuación, se plantean las consideraciones metodológicas que derivan en la presentación de los resultados. En el apartado final, se presenta una discusión y varias reflexiones para futuros trabajos dentro de esta temática.

\section{La música: un antídoto al aislamiento social y una fuente de bienestar personal y social.}

La música es un elemento cultural que cumple diferentes funciones en la sociedad moderna. Se trata del recurso primario de entretenimiento (Bennett, 2001) y también de una vía para representar la realidad de la sociedad (Silva, Guerra y Santos, 2018). De la misma manera, la música puede suponer un apoyo emocional y de conexión que incentive el bienestar. Y es precisamente esta última característica la que ha destacado durante la crisis de la COVID-19, como indica Partida Valdivia (2020):

El fenómeno actual del coronavirus es un suceso fuera de lo común, en el que la música aparece como un aliciente para contrarrestar ese escenario de perplejidad y desasosiego. Aquí, cabe mencionar la importancia de la música no solo para generar un ambiente placentero o incentivar un estado de tranquilidad (...), sino para conectarnos y acercarnos con otros a pesar de que las circunstancias actuales requieren un necesario distanciamiento social. (Partida Valdivia, 2020, p.15)

En buena medida, el distanciamiento social y las disposiciones gubernamentales, como la de "quedarse en casa", despertaron ansiedad en relación a la salud, la preocupación financiera y, por supuesto, los sentimientos de soledad en varios grupos sociales (Tull et al., 2020). De acuerdo con Tull et al. (2020), es importante lograr una conexión social para mitigar las consecuencias psicológicas negativas de la pandemia de la COVID-19. Esta conexión social es un elemento trascendental en la vida de niños y jóvenes, pues forma parte del desarrollo de sus capacidades de identificación (Erikson, 1994; Hall, 1996). Sin embargo, también es importante considerar a los grupos sociales de jóvenes adultos y los adultos mayores pues, como menciona el estudio de Beam y Kim (2020) son quienes podrían sufrir mayores secuelas psicológicas a partir del aislamiento social y la soledad. En este sentido, el estudio de UNICEF (2020) señala como uno de los principales efectos de la pandemia $y$, en particular, del confinamiento domiciliar, el deterioro de la salud física y mental.

Según la Organización Mundial de la Salud, la salud mental se define como un estado de bienestar en el que la persona desarrolla sus capacidades y es capaz de hacer frente al estrés normal de la vida, de trabajar de forma productiva y de contribuir a su comunidad. Ese estado de bienestar afecta el cómo pensamos, sentimos y actuamos; y determina cómo respondemos frente al estrés, cómo nos relacionamos con los demás y en qué medida (o de qué manera) tomamos decisiones. El bienestar psicológico, que incluye tres dimensiones interrelacionadas: la personal, la interpersonal, además de las capacidades y conocimientos (Diener, Lucas y Oishi, 2018), es un factor importante a tener en cuenta, especialmente en un situación de crisis como la gene- 
rada por la COVID-19, pues los sentimientos de angustia y preocupación se exacerberan.

En la respuesta psicológica, que se desarrolla ante una situación de emergencia, influyen distintos factores entre los que destacan la autoconfianza, la capacidad de expresar nuestros sentimientos y estados de ánimo, además de la red de apoyo social. A esto se suma el impacto que juegan las condiciones socioeconómicas y habitacionales de cada persona, así como las condiciones familiares y personales particulares. Por todo esto es que, en muchos casos, se considera que la experiencia del confinamiento y la pandemia es muy personalizada y altamente subjetiva.

No obstante, más allá de las múltiples particularidades y casuísticas existentes, se ha podido percibir en las sociedades del mundo, sentimientos muy básicos y comunes como el miedo, la necesidad de encontrar apoyo y compañía en nuestros iguales, además del agradecimiento a los profesionales sanitarios y otros colectivos considerados como esenciales. Así mismo, se ha podido observar a muchas personas que han mostrado un nivel alto de altruismo, cooperación, y satisfacción al ayudar a los demás (Cano-Hilla y Argemí, 2020). Por ejemplo, a través de acompañar a las personas solas (por teléfono o a través de otros canales de comunicación), e incluso realizando gestos de ánimo hacia las personas aisladas o hacia los profesionales sanitarios, tal como ha tenido lugar en España, por medio de la canción "Resistiré 2020", coincidiendo con los aplausos de cada día, a las 20:00 horas.

Con la intención de lograr y fortalecer la conexión social en tiempos de confinamiento, las artes han jugado un papel trascendental. Ver, hacer y compartir música (además de otras prácticas artísticas), sirve como vehículo terapéutico. En primer lugar, porque ayuda a proteger la salud física, propiciando movimiento y actividad; en segundo lugar, fortalece el bienestar personal, mejorando la confianza y el optimismo; en tercer lugar, contribuye al bienestar interpersonal, reforzando la solidaridad, el apoyo social y la acción colectiva; y, en cuarto lugar, fortalece el desarrollo de capacidades y conocimientos relacionados con la superación de retos y la expresividad de las emociones. En definitiva, las artes en general, y la música en particular, proporcionan una especie de antídoto complementario y fortalecedor del bienestar y de la salud mental de la ciudadanía (Gupta, 2020). De acuerdo con el estudio de Zhao et al. (2020), las prácticas literarias y artísticas produjeron una influencia social positiva y desempañaron un rol fundamental para movilizar la fuerza social en medio de la crisis de la pandemia.

Si volvemos a las reflexiones de Partida Valdivia (2020), coincidimos en que hacer o escuchar música refleja una manera de vivir y se convierte en una experiencia que trasciende a lo que podemos expresar con palabras. Así mismo, tanto el hacer como el escuchar están condicionados por un tiempo y espacio particular, y vinculan aspectos individuales tales como recuerdos, motivaciones y propósitos de vida. Sin embargo, estos aspectos individuales también trascienden hacia lo colectivo, ya que la música congrega también funciones sociales (Zhao et al., 2020). Es en este sentido en que las emociones juegan un papel muy relevante, pues un evento de las dimensiones de la pandemia de la COVID-19 contribuye, en efecto, a construir una fuerte asociación emocional (Smith y Mackie, 2015)

Si bien podría ser un error considerar a la audiencia en confinamiento como grupos uniformes que comparten las mismas prácticas y comportamientos (García Canclini, 2001), las condiciones textuales, extratextuales, estéticas y sociales (que se destacan al momento de analizar una creación artística), han puesto en evidencia un conjunto de características comunes que permean en la sociedad y generan un sentimiento de identificación (Hall y Du Gay, 2003); un sentimiento, más o menos generalizado, hacia ciertas emociones y prácticas de algunos grupos sociales (Fontana Sierra, 2020). En otros grupos, sin embargo, se han puesto sobre la mesa las condiciones de discriminación social que han tenido que afrontar durante la crisis de la pandemia (Ortuño et al., 2020; Palazuelos Covarrubias y Zamora Saenz, 2020; Rojo-Gutiérrez y Bonilla, 2020).

Los sentimientos y emociones que se generan en un escenario de incertidumbre y desesperación se pueden constituir como espacios que procuran un contacto, afecto, empatía y vinculación que, aunque fugaces, "son reales y suficientes para subvertir el malestar provocado por la pandemia" (Fontana Sierra, 2020, p. 112). En este sentido, la música se puede entender como una herramienta que estimula el vínculo, protege y restaura la salud mental y el bienestar personal y social, al tiempo que fortalece los lazos sociales (Rimé, 2009) y la acción colectiva, particularmente en momentos de crisis. Las emociones que se plasman en los productos artísticos son, en buena medida, en las que la audiencia se reconoce. Según Joan Ferrés (2014), las narraciones mediáticas únicamente tienen valor cuando las personas que interaccionan con ellas se ven representadas en ellas. Es decir, tienen sentido cuando las personas ven un reflejo de ellas mismas, de sus emociones y sentimientos. Y es a través de este ejercicio 
que se convierten en el medio por el cual se desconecta, de alguna manera, de la ansiedad y el miedo generados por el virus. "Es posible identificar un proceso comunicativo establecido entre intérpretes y oyentes, en el que se pretende transmitir un mensaje de empatía en medio de la crisis sanitaria" (Partida Valdivia, 2020, p. 14)

La dinámica interpersonal de intercambio social de emociones (Rimé, 2009, p. 71-72) se refiere a las consecuencias interpersonales, tanto en lo cognitivo como en lo social, entre quienes reciben una emoción compartida con la que pueden interactuar. El autor sostiene que, a través de esta práctica, se pueden poner en manifiesto cinco respuestas: la del interés, el contagio emocional, la empatía y simpatía, comportamientos de apego, y un mayor afecto hacia el narrador. Si miramos las piezas musicales como productos narrativos que (re) presentan emociones y prácticas que, a su vez, conectan con las audiencias provocando algunas de las citadas respuestas, podemos coincidir en que la música facilita la participación y conecta con la capacidad social que marca una diferencia (Gupta, 2020), especialmente en un escenario de crisis.

\section{Metodología y análisis}

Las preguntas de investigación que guían este estudio son: ¿qué elementos, acciones, situaciones y emociones están presentes en las narraciones sobre el confinamiento? y ¿cómo estas narraciones están conectadas a su vez con su audiencia y el escenario de crisis derivado de la COVID-19?

Este estudio analiza el mix tape "Desconfinamiento" de Stay Homas, que consiste en una recopilación de sus cinco temas más populares: "In the end", "The bright side", "Gotta be patient", "Estamos mal" y "Volveré a empezar". El orden en que estos temas han sido presentados en su canal de YouTube ${ }^{3}$ coincide con una narrativa que se puede entender como secuencial, tomando en consideración que cada canción da paso a la siguiente en base a las emociones, elementos y reflexiones del tiempo en confinamiento, como si se tratara de un día a día (o semana a semana). Por esta razón, este estudio considera a las canciones del grupo como narraciones personales.

Para responder a nuestras preguntas, se realiza un análisis cualitativo de texto (Krippendorff, 2004, p. 341) en el que se examina de manera inductiva qué emociones y elementos se encuentran en las narraciones de Stay Homas. Alineado con nuestro objetivo de analizar este fenómeno social, se siguen los principios de la Teoría Fundamentada (Grounded Theory) (Glaser y Strauss, 1967). Según este enfoque, las catego- rías de análisis pueden desarrollarse interactivamente en paralelo con el material fuente de análisis antes de abordar cualquier teoría. Esto significa que la teoría emerge de los datos, ya que se les permite hablar por ellos mismos, en lugar de aplicar marcos conceptuales y/o teóricos, preexistentes. Siguiendo esta teoría, el análisis de los datos se organizó en dos fases.

En una primera fase, el texto de las canciones se compiló en una taxonomía descriptiva desarrollada a partir de la relectura y comparación de las diferentes instancias presentes en los textos. Las categorías surgieron inductivamente y se centraban en identificar los elementos, personas, prácticas, acciones y emociones presentes en las narraciones. Estas primeras categorías descriptivas se reagruparon, a posteriori, en la segunda fase, en categorías interpretativas. La lógica del proceso era pasar de una perspectiva "micro" a una perspectiva "macro". Las categorías y los datos fueron producidos, examinados y revisados continuamente hasta el final del estudio. El análisis se llevó a cabo a través del software de análisis cualitativo NVivo 12.

A partir del análisis, se detectaron cinco categorías centrales que responden a las preguntas formuladas. Éstas son: 1) deseos: donde se engloban las actividades que se desarrollaban previo a la cuarentena y que, en medio de la crisis, se anhelan con cierta insistencia; 2) emociones: subdividida en "positivas", "negativas", "inciertas" o "de añoranza"; 3) personas: donde la familia y las amistades se convierten en el papel principal; 4) prácticas: que detallan la experiencia durante el confinamiento; y 5) reflexiones: que, de modo esperanzador, procuran una contraposición entre el tiempo pre-pandemia y el futuro.

\section{Resultados: Una lectura al (Des)confinamiento}

A partir de los análisis realizados, tal y como se mencionaba anteriormente, emergen cinco categorías analíticas, las cuales se desarrollan a continuación:

\subsection{Deseos: de la realidad cotidiana a la fantasía identificable.}

Cuatro de las cinco canciones analizadas tienen referencias importantes hacia actividades que los intérpretes quisieran realizar, entre las que priorizan: viajar, salir a la calle, salir de fiesta (con los amigos), y olvidar la situación actual. Estos elementos están presentes en su narración desde la primera canción de Desconfinamiento, lo que dialoga muy bien con las restricciones que supone la cuarentena. Los deseo son sencillos y se focalizan en situaciones cuotidianas realizadas en tiempos de 'normalidad', como tomar un café acom- 
pañado/a. Curiosamente, estas actividades rutinarias se entremezclan con referencias a figuras de la ficción conocidas y fáciles de identificar (como Han Solo de la Guerra de las Galaxias), a lugares fantásticos (como Disney Land), o a espacios de diversión que se recuerdan, en cierto modo, de una manera romántica (por ejemplo, Apolo, una sala de conciertos y fiestas en Barcelona).

De esta manera, observamos que los deseo se mueven en dos direcciones: a) volver a vivir la realidad cuotidiana; y b) dibujar una fantasía identificable. Estos elementos juegan un rol de identificación importante en la audiencia con la que comparten su música. Por una parte, la audiencia encuentra representada una realidad 'compartida' que impide vivir en 'normalidad' y, por lo tanto, apela al deseo común de volver a la cotidianidad, a los momentos sencillos que ahora se echan de menos, a aquello a lo que ahora se otorga valor. Solo se desea volver al 'antes'. Y esto se hace desde la empatía compartida. La canción Volveré a empezar, resulta interesante en este sentido:

Lo que daría por un café contigo / Arreglar el mundo sin llegar a ningún sitio / Mirar la luna y saber que estás aquí conmigo / Ahora quiero verte más, quiero ir a cenar / Dejar las tonterías y por fin poder llamar / Te lo prometo que muy pronto llegará.

(Volveré a empezar, Stay Homas, 2020)

Por otra parte, en tiempos de crisis e incertidumbre, presentar fantasías identificables puede ayudar a la audiencia a dibujar horizontes compartidos hacía los que caminar. $Y$, para ello, es necesario representar espacios y figuras fantásticas que la audiencia reconoce y da valor. Disney, en este sentido, se concibe como un espacio mágico donde viven los personajes con los que hemos pasado nuestra infancia. Es un lugar para soñar donde todo es posible. Y, también, un lugar que todo el mundo puede reconocer e identificar como un espacio ideal con el que soñar en tiempos de crisis.

\subsection{Emociones: una mirada positiva a la crisis que no puede olvidar el malestar y la incertidumbre.}

Esta es la categoría más extensa del análisis. Dentro de "emociones", el estudio ha creado cuatro subcategorías: Positivas, negativas, inciertas y de añoranza.

Las emociones positivas pueden alimentar los lazos existentes entre quienes comparten una experiencia (Rimé, 2009, p. 65). En las letras analizadas, estas emociones están presentes en la mayor parte de las canciones, y se encuentran en frases que invitan a mantener la calma y ser pacientes ante la situación actual, procurando, a la vez, concientizar sobre la importancia de la autoestima y la vida como un regalo. En este sentido, por ejemplo, el tema The brigth side reúne una serie de frases que invitan a la reflexión alrededor de la libertad a partir de abrazar la individualidad, pero también la colectividad:

Si ves el lado positivo / Serás libre / Encontrarme a mi es el mejor regalo que tengo / Olvidémoslo esta noche / Ya verás / Encontrarte a ti es el mejor regalo que tengo. [If you see the bright side / You'll be free / Trobar-me a mi és el millor regal que tinc / Let's forget it tonight / You will see / Trobar-te a tu és el millor regal que tinc.]

(The bright side, Stay Homas, 2020)

De esta manera, se intenta buscar el lado "positivo" de la situación, la oportunidad para pensarse y encontrarse a uno mismo, pero también para reflexionar sobre el valor que "los otros" tienen para nosotros; una combinación entre lo individual y colectivo. La idea es "hacer una mirada positiva" de una situación complicada y difícil de llevar adelante.

Por su parte, las emociones negativas, que pueden estimular un intercambio social e incrementar el sentimiento de afecto, son minoritarias en las canciones analizadas. Estas emociones reflejan, principalmente, el cansancio de la rutina en confinamiento:

"Estoy harto del drama" ['I'm so sick and tired of drama'] / "Yo no quiero vestir pijamas" [I don't wanna wear pijamas]

(In the end, Stay Homas, 2020)

Como observamos, las emociones positivas vienen acompañadas de una visión/emoción más negativa (aunque minoritaria). Podría ser que un abuso de visión "positiva" se asociara a una mirada "naif" o "ingenua" de la situación. En cambio, estas inyecciones de emoción negativa parece que nos vuelven a la realidad y también encuentran una identificación, ya que en tiempos de crisis es difícil mantener continuamente "la mirada positiva".

Las emociones inciertas, por su parte, suponen un estado de inseguridad que, dicho sea de paso, mantiene cierto tipo de positivismo, aunque están vinculadas de manera irónica con calificativos negativos. Las emociones inciertas, en las canciones analizadas expresan, en general sentimientos difíciles de determinar cómo positivos o negativos, especialmente porque el ritmo que las acompaña es enérgico. Por ejemplo, en la canción In the end, que es el primer 
tema de Desconfinamiento (que inicia con la narrativa de la incertidumbre), encontramos letras como: "No sé qué decir" ['I don't know what to say'] (In the end, Stay Homas, 2020) y, en la canción "Estamos mal" se juega con la ironía y el doble sentido: "Estamos mal, pero es lo normal" / "Que estés en la mierda es lo más natural" (Estamos mal, Stay Homas, 2020).

Especialmente apropiada e identificable es la incertidumbre, en el caso que nos ocupa pues, si algo caracteriza la crisis que vivimos es la incerteza sobre el futuro que nos espera. No tener palabras o respuesta ('no sé qué decir') y normalizar los sentimientos inciertos que nos provoca la crisis, puede ser una nueva vía de identificación con la audiencia. Una audiencia que busca respuestas pero que difícilmente las encuentra $y$, de nuevo, puede evidenciar que se trata de un sentimiento compartido.

Finalmente, en la categoría añoranza, se reúnen las expresiones que tienen vinculación directa con la emoción de extrañar a una persona o una actividad. Así, las referencias a "añoranza", por ejemplo, están presentes desde la primera canción de Desconfinamiento. El tema In the end pone principal énfasis a todas las prácticas que se han dejado de hacer en cuarentena, como se ha expuesto ya. Sin embargo, el énfasis de añoranza principal se dirige hacia la figura de la madre, sobre todo, y de manera insistente, al final de la canción, cuando ésta dice: Yo realmente, realmente, realmente, realmente extraño a mi mamá [ I really really really really miss my mum]. Se tratan de emociones estrechamente vinculadas al 'deseo' de vuelta a la realidad cotidiana que se analiza en la sección anterior. La crisis de la COVID-19 ha parado en seco todas nuestras rutinas y actividades cotidianas y hemos tenido que aprender a vivir una nueva vida sin "previo aviso". Esto, necesariamente, promueve una mirada al "pasado" que es melancólica y de añoranza. Frente a la falta de un imaginario futuro compartido, la imagen del pasado nos resulta romántica y se acaba idealizando. Esta situación o sentimiento se incrementa notablemente cuando la nueva situación no ha sido escogida, como es el caso que nos ocupa.

\subsection{Personas: la necesidad del vínculo cercano.}

Dos de las cinco canciones analizadas hacen una referencia directa hacia las personas a quienes, en general, se extraña. Este ámbito está copado mayoritariamente por las personas más próximas: amigos/as y familia. Las amistades conforman un nexo social importante $y$, a través de las prácticas compartidas, es posible fortalecer los elementos que juegan en el proceso de identificación y la construcción de la propia identidad.
Si la vinculación social se afecta, como sucede con el distanciamiento (a partir de la cuarentena), también se afectan algunos procesos de identificación y relación. La presencia de "amigos/amigas", en las canciones de Stay Homas, es la más generalizada y permite comprender que, por medio de prácticas con los pares, es posible eludir la situación y, de alguna manera, sobrellevar la rutina del confinamiento.

Sin embargo, la insistencia -como se menciona en la categoría anterior- con relación a extrañar a la madre, denota una mayor importancia hacia este personaje (sin dejar de lado a las hermanas o hermanos). De hecho, al menciona a la madre, todos los otros elementos e ideas que están presentes en la canción In the end parecen diluirse de algún modo, pierden relevancia y el interés se centra, casi exclusivamente, en ella.

Cuando analizamos a las personas, en la narrativa de Stay Homas, podemos comprender que se habla desde un confinamiento (casi) en solitario o, al menos, lejos del núcleo familiar. En un momento donde factores como la soledad, la angustia y el encierro marcan el día a día, los lazos familiares se vuelven indispensables para afrontar el conflicto en el que entra el individuo. La madre, en este sentido, hace referencia a la figura que brinda el mayor grado de seguridad y apoyo para afrontar la vulnerabilidad ante la crisis.

Al referirnos a un confinamiento en "solitario" no enfatizamos únicamente la ausencia de una figura presencial (física) que acompañe el día a día, sino de la sensación de soledad que se llena a partir de la interrelación con las personas a quienes más se quiere y con quienes más vivencias positivas se tiene. De ahí que dar tanta importancia y repetición a la madre se percibe como una urgencia para llegar a una situación no sólo de compañía sino de calma y tranquilidad, que coincide con la breve presentación del video de la canción, en el canal de YouTube de los artistas:
"Esta canción trata de ser una reflexión sobre lo que creemos que extrañamos y lo que realmente extrañamos (...) Realmente extrañamos a nuestra madre, ¿y tú?" [This song tries to be a reflection on what we think we miss and what we really miss (...) We really miss our mum, and you?]
(In the end, Stay Homas, 2020)

Dentro de la categoría de "personas", Stay Homas también hace referencia a "los otros", lo que pone en evidencia el cómo nos construimos como personas a partir de lo que hace el otro. Ya sea en actividades o teniendo en cuenta las emociones, la identificación con otras personas trasciende el plano individual y, en 
la colectividad, encuentra sentido en la realidad que se comparte. Este proceso permite catalizar las emociones de angustia y temor porque, de alguna manera, la identificación y el compartir la misma situación crea una ilusión de que "no somos los únicos" y, por tanto, "no estamos solos en esto."

Finalmente, Stay Homas utiliza, en dos de las cinco canciones analizadas, una estrategia de autopromoción que ingresa también en la categoría de personas pues materializa al trío artístico que, precisamente, es el que narra su experiencia a través de las canciones. Así, por ejemplo, se encuentran las frases: "pero por suerte Stay Homas sacan nueva canción." (Estamos mal, Stay Homas, 2020) y "Pero con los videos de estos tres" [Però amb els vídeos d'aquests tres] (Gotta be Patient, Stay Homas 2020). Esta estrategia no sólo les permite poner su firma en los productos musicales que crean, sino que, de cierta manera, los promueve como figuras 'a identificar' (a seguir) cuando se busca un vínculo social y compartir (o sentirse comprendido/a) emocionalmente durante el tiempo de crisis.

\subsection{Prácticas: uniformizar y homogeneizar el día a día.}

Después de las categorías de "deseos" y "emociones", las "prácticas" ocupan el tercer lugar de importancia dentro de las letras de las canciones de Desconfinamiento. Cuatro de las cinco canciones detallan, y con bastante precisión, un día a día dentro de su experiencia. Esta narrativa coincide muy bien con algunas ideas que cita el trabajo realizado por Fontana Sierra (2020, p.105) en relación a aquellas "nuevas ocupaciones" que se han integrado a la vida de diferentes grupos sociales en España, desde la cuarentena: "ejercicio, yoga, pintar, tocar instrumentos, aprender idiomas, leer, jardinería, cocinar", entre otras. En este sentido, la canción Estamos mal es el ejemplo más relevante:

"Me levanto de la cama / me huele el wichiwama / Llevo así ya dos semanas / Tocando la palangana / Los platos sin fregar / No me levanto del sofá / Y si me mandas otro challenge lo va hacer tu mamá / Todo el mundo hace pilates, hace zumba y hace yoga / Y la receta de un bizcocho y muffins con leche de soja / El móvil echando humo / Un concierto en el salón / y te juro que hoy he visto una tuba en un balcón / Películas, libros y vídeollamadas / Estática, elíptica o abdominales / A veces incluso haciendo chorradas por encima de vuestras posibilidades / Ya me he visto todo HBO /

(Estamos mal, Stay Homas, 2020)

De nuevo, observamos la búsqueda de la identificación a través de la representación de las prácticas "posibles" durante el confinamiento. La crisis de la COVID-19 conlleva que todos veamos limitadas las actividades que podemos hacer en el día a día. Esto facilita las representaciones de prácticas y situaciones compartidas. Cualquier persona que ha vivido el confinamiento puede encontrar en Estamos mal alguna actividad de su rutina diaria porque se trata de elementos limitados. Además, se realiza una referencia explícita a esta rutina compartida e identificable cuando el grupo dice "todo el mundo hace". Así mismo, la lista de actividades intenta abarcar el abanico de prácticas posibles que puede realizar la gente durante el confinamiento.

Esto, en contrapartida, puede promover una representación uniformizada de las prácticas diarias durante el confinamiento. Parece ser que "todo el mundo", en efecto, lleva a cabo estas prácticas y que la excepción es quien no las hace. Querer representar la realidad del confinamiento a través de una lista reducida de actividades y prácticas que se "supone" todos hacen, puede conllevar una representación homogeneizada de la realidad social, que va más allá de la edad, del género e, incluso, de la locación. Sin embargo, esto reduce la complejidad de la situación a una mirada concreta, simplificando la realidad de varios grupos sociales donde los efectos del confinamiento han minado aún más la desigualdad económica, educativa y de oportunidades (Palazuelos Covarrubias y Zamora Saenz, 2020, p. 7).

\subsection{Reflexiones: repensarnos y cambiar las dinámicas del pasado para empezar a 'vivir de verdad'}

Finalmente, considerando la reflexividad que posibilita la música a partir de su discurso, el estudio también identifica algunas intenciones de cambio generadas a partir del confinamiento. La canción The brigth side, así como Volveré a empezar, son los temas que más reflexiones hacen al respecto de la "normalidad" que ha cambiado a partir de la crisis y el confinamiento. Ambas canciones tienen un tono esperanzador y se observa una tendencia a dibujar un escenario donde las cosas serían diferentes, donde se podrá "volver a intentar":

"Vivimos cada día como si fuera el final / Nunca hay tiempo para ver a quien queremos de verdad / La rutina nos ahoga y no podemos parar / No he valorado el amor que me das / Ya no sé de ti ya no te he vuelto a llamar / Ya no sé si te voy a perder, lo volveré a intentar / Todo este tiempo me ha dado 
por pensar / que llegado el momento voy a vivir de verdad / Cuando salga de aquí yo quiero verte más."

(Volveré a empezar, Stay Homas, 2020)

Observamos que, en cierto modo, la situación actual nos lleva a replantearnos nuestras actitudes, comportamientos y actividades del pasado. La crisis promueve una "reflexión" alrededor de la vida en sí y la manera como queremos vivirla. Esta situación también supone que podríamos pensar en las cosas que realmente importan y darles valor. Se trata de una reflexión "popular" durante la crisis: la necesidad de replantearse la forma de vida que llevábamos, de detectar los 'valores' y brindarles mayor importancia. El modelo a seguir en este caso, y con él que concluye la reflexión, sería el 'carpe diem': aprovecha el momento y vive la vida. Esto coincide con la declaración de intenciones: "llegado el momento voy a vivir de verdad", dando a entender que las dinámicas que teníamos antes no eran "óptimas" o no nos ayudaban a vivir "de verdad".

\section{Discusión y reflexiones finales}

Los resultados de este estudio se engloban en cinco categorías que narran de manera secuencial un escenario del confinamiento derivado de la pandemia por la COVID-19 en España, mismas que han sido desarrolladas a partir del mix tape Desconfinamiento, de Stay Homas. Estas categorías son 1) deseos, 2) emociones (positivas, negativas, inciertas y de añoranza), 3) personas, 4) prácticas y 5) reflexiones que, en conjunto, constatan cómo, en el contexto pandémico confinado - insólito y de incertidumbre-, la música -en general-, y la música producida por Stay Homas -en particular-, se presentan como un recurso cultural clave que aporta entretenimiento (Bennett, 2001), a la vez que funciona como una vía para representar la realidad social (Silva, Guerra y Santos, 2018), actuando como un vehículo terapéutico, tanto a nivel físico como a nivel emocional.

El artículo pone en evidencia cómo la música de Stay Homas conecta, desde el plano individual, con varios sentimientos, nuevos hábitos y prácticas sociales del confinamiento, entre los que destacan las emociones positivas y una retórica discursiva de tono esperanzador, así como algunas "nuevas actividades" que derivan del tiempo en confinamiento y que se convierten en prácticas sociales fáciles de identificar. En el plano colectivo, Stay Homas conecta con un discurso alentador que enfrenta la angustia y la soledad derivadas de la crisis, a través de invitaciones a la calma y la paciencia, o incluso a repensar la vida y el modo de vivirla.

El estudio destaca, tal y como apuntan los trabajos de Tull et al. (2020) y Beam y Kim (2020), que es importante lograr una conexión social para mitigar las consecuencias psicológicas negativas de la pandemia de la COVID-19, esencialmente provocadas por del aislamiento social y la soledad, sentimientos y estados que el estudio identifica en la narrativa de "Desconfinamiento". Dicho de otro modo, y en la línea que plantean otros trabajos (Gupta, 2020; Zhao et al., 2020), la evidencia empírica constata que la música se puede entender como una herramienta que estimula el vínculo, protege y restaura la salud mental y el bienestar personal y social, al tiempo que fortalece los lazos sociales (Rimé, 2009) y la acción colectiva, particularmente en momentos de crisis.

En su narrativa, las canciones de Stay Homas reconocen emociones de angustia, rutina, nostalgia, cansancio y, sobre todo, la necesidad de los seres queridos. Pone énfasis en prácticas cotidianas que se extrañan durante el tiempo de confinamiento, dando una importancia aún mayor a las personas a quienes se desea volver a ver. Al referirse al núcleo familiar, representado principalmente por la figura de la madre, Stay Homas pone sobre la mesa las condiciones de vulnerabilidad que se viven desde el primer momento de la cuarentena, y las enlaza con elementos populares y fantásticos que permiten catalizar la incertidumbre a través del deseo y la idealización hacia el pasado.

Estos sentimientos desembocan en una reflexión sobre el modo de vida que se ha llevado previo a la crisis, donde se permiten repensar las prioridades y lo que de verdad puede o no darle sentido a la existencia, para esbozar así una suerte de "propósitos" a alcanzar a futuro. Incluso aquellas emociones negativas, propias de la saturación de información y malestar generalizado, se leen entre líneas como puntos de partida hacia cambios que se podrían iniciar al término del confinamiento, en busca de una mejor vida en la "nueva normalidad" que tanto se comenta.

En este sentido, es relevante referirnos a la audiencia de Stay Homas pues, al analizar la narrativa de sus canciones, se pone en evidencia que sus letras pueden conectar tanto con niños y jóvenes, así como con adultos y adultos mayores, independiente de su género y localización. Este efecto, casi homogeneizador, es particular en el caso del trío catalán, como ellos mismos han reconocido. Sin embargo, es precisamente esta particularidad la que nos ayuda a comprender su impacto y éxito. La mayor parte de su mensaje (que además se desarrolla en tres idiomas) se transmite de manera 
positiva y con ritmos alegres, y es lo que los convierte en "un antídoto" que facilita la identificación de las emociones para sobrellevar la situación de la crisis.

Si bien el caso de producción musical en tiempos de pandemia y confinamiento no es exclusivo de Stay Homas, pues otras creaciones también han llamado la atención de los medios de comunicación, como es el caso de Rigoberta Bandini (Crespo, 2020), el trío catalán nace dentro del contexto de confinamiento, con el propósito de acompañar a su audiencia (igualmente confinada), mientras las letras de sus canciones hacen una referencia directa a la situación derivada de la crisis de la COVID-19. Es en este sentido en que sus piezas musicales favorecen la conexión social con su audiencia, lo que desencadena una dinámica de intercambio social de emociones (Rimé, 2009) que, a su vez, facilita la participación y la capacidad social, por medio de respuestas vinculadas con la empatía, el apego, el afecto, especialmente en un momento tan determinante como el confinamiento.

Finalmente, este estudio considera que es importante, en futuras investigaciones, incorporar un análisis de percepción e impacto desde las audiencias que reciben y consumen los productos culturales como la música, para ampliar la argumentación crítica y promover el diálogo que contribuya a formar una sociedad más justa, inclusiva, reflexiva y empática. En este sentido, se pone en valor las piezas musicales, tanto respecto a su narrativa como a su representación (particularmente en tiempos complejos), como vehículos que promueven el apoyo emocional y el bienestar social, mientras fungen como como un canal de representación de la realidad social. La música, sus letras y representaciones, es en sí misma un dato y un instrumento privilegiado de recogida de evidencias empíricas en el marco de las ciencias sociales y humanas.

\section{Notas al final}

1. Disponible en: https://www.youtube.com/watch?v=LIWWT-eKOwU\&t=365s

2. Disponible en: https://www.youtube.com/watch?v=hWa910JHpGMEt $=1808 \mathrm{~s}$

3. Disponible en: https://www.youtube.com/channel/UCOPtwzSikWRnftscW9ul_Ug/videos

\section{Referencias}

Beam, C. R., y Kim, A. J. (2020). Psychological Sequelae of Social Isolation and Loneliness Might Be a Larger Problem in Young Adults Than Older Adults. Psychological Trauma: Theory, Research, Practice, and Policy. https://doi.org/10.1037/tra0000774

Bennett, A. (2001). Cultures of Popular Music. (S. Allan, Ed.). Marston Book Services Limited, Oxford.

Cano-Hila, A. B., y Argemí-Baldich, R. (2020). Taking Care of Us from the Neighborhoods in Times of Quarantine. Citizen Solidarity Practices in Vallcarca, Barcelona (Spain). Space and Culture, 23(3), 237-245. https://doi.org/10.1177/1206331220938633

Crespo, Pablo. (10 septiembre 2020) Entrevista a Rigoberta Randini, autora de la imprescindible "in spain we call it soledad". Carretera y Manta. Publico. https://carreteraymanta.publico.es/entrevista-arigoberta-bandini-autora-de-la-imprescindible-in-spain-we-call-itsoledad/

Díaz, L. (24 junio 2020). Stay Homas: "El confinamiento para nosotros ha sido el nacimiento, pero para la música una hostia en toda la cara. Infolibre. https://www.infolibre.es/noticias/cultura/2020/06/24/ stay_homas_confinamiento_para_nosotros_sido_nacimiento_pero_ para_musica_una_hostia_toda_cara_108097_1026.html

Diener, E., Lucas, R. E. and Oishi, S. (2018) 'Advances and open questions in the science of subjective well-being', Collabra: Psychology, 4(1), 1-49. https://doi.org/10.1525/collabra.115

Erikson, E. H. (1994). Identity Youth and Crisis. W. W. Norton \& Company.

Ferrés, J. (2014). Las pantallas y el cerebro emocional. Gedisa.

Fontana Sierra, L. (2020). Pandemia y rearticulación de las relaciones sociales. Perifèria, Revista de Recerca i Formació En Antropologia, 25(2), 101-114.

García Canclini, N. (2001). Culturas híbridas. Estrategia para entrary salir de la modernidad. Paidós.

Glaser, B. G., y Strauss, A. L.(1967). The Discovery of Grounded Theory: Strategies for Qualitative Research. Aldine.

Gómez Gerez, A., Millan Hernández, A., Estupiñá Vilas, G., Sistac Garica, H., Albos Iscla, J., y Martí Álvarez, N. (2020). El control en los tiempos del coronavirus. Perifèria, Revista de Recerca i Formació En Antropologia, 25(2), 203-215.

Gupta, N. (2020). Singing Away the Social Distancing Blues: Art Therapy in a Time of Coronavirus. Journal of Humanistic Psychology, 1-11. https://doi.org/10.1177/0022167820927807

Hall, S. (1996). Who needs "identity"? En Hall, S., y du Gay, P. (eds.) Questions of Cultural Identity (pp. 1-17). Sage Publications.

Hall, S., y Du Gay, P. (2003). Cuestiones de Identidad Cultural. Amorrortu, Editores.

Hernández, Y. M., y Pedraza, G. R. (2020). Música maestro, escenarios virtuales en tiempos del COVID-19. Perifèria, Revista de Recerca i Formació En Antropologia, 25(2), 154-166.

Illescas, J. E. (2015). La dictadura del videoclip. El Viejo Topo.

Krippendorff, K. (2004). Content Analysis. An Introduction to its Methodology (2ed.). Sage Publications.

Lehman, E. T. (2020). "Washing Hands, Reaching Out" - Popular Music, Digital Leisure and Touch during the COVID-19 Pandemic. Leisure Sciences, O(0), 1-7. https://doi.org/10.1080/01490400.2020.1 774013

Linés, E. (21 junio 2020). Día de la música: Las mejores canciones de este año. La Vanguardia. https://www.lavanguardia.com/ musica/20200621/481878893273/dia-de-la-musica-50-exitos-coronavirus-2020.html

Ortuño, A., Pineda, C., Montes, D., Martin, D., Lameda, F., García de Vicuña, H., y Alvarado, L. (2020). Coronatextos. Reflexiones virales. Omnia Sunt Communia. https://doi.org/10.1017/ CB09781107415324.004 
Palazuelos Covarrubias, I., y Zamora Saenz, I. (2020). Aproximación al ánimo social en los hogares de México en el contexto de la crisis sanitaria: prioridades, preocupaciones y expectativas de la población. Temas de la Agenda, (16), 1-8. Instituto Belisario Domínguez del Senado de la República.

Partida Valdivia, J. M. (2020). Relación de sintonía mutua ante la contingencia sanitaria del Covid-19: un breve análisis fenomenológico sobre la música. Programa Universitario de Estudios sobre Democracia, Justicia y Sociedad. UNAM

Rimé, B. (2009). Emotion Elicits the Social Sharing of Emotion: Theory and Empirical Review. Emotion Review, 1(1), 60-85. https://doi. org/10.1177/1754073908097189

Rojo-Gutiérrez, M. A., y Bonilla, D. M. (2020). COVID-19: La necesidad de un cambio de paradigma económico y social. CienciAmérica, 9(2), 77-88. https://doi.org/10.33210/ca.v9i2.288

Santos, N., Bac, M., y Elorrieta, G. (13 mayo 2020). Canciones para animar la cuarentena. Timeout.es. https://www.timeout.es/madrid/ es/musica/canciones-cuarentena

Silva, A. S., Guerra, P., y Santos, H. (2018). When art meets crisis: The Portuguese story and beyond. Sociologia, Problemas e Praticas, (86), 27-43. https://doi.org/10.7458/SPP20188611860

Smith, E. R., y Mackie, D. M. (2015). Dynamics of Group-Based Emotions: Insights from Intergroup Emotions Theory. Emotion Review, 7(4), 349-354. https://doi.org/10.1177/1754073915590614

Stay Homas, revelación en el confinamiento, anuncia gira y recalará en Madrid. (3 julio 2020). La Vanguardia. https://www.lavanguardia.com/vida/20200703/482062576685/stay-homas-revelacion-en-el-confinamiento-anuncia-gira-y-recalara-en-madrid.html

Stay Homas. (2020). Stay Homas. https://es.stayhomas.org

Tull, M. T., Edmonds, K. A., Scamaldo, K. M., Richmond, J. R., Rose, J. P., y Gratz, K. L. (2020). Psychological Outcomes Associated with Stayat-Home Orders and the Perceived Impact of COVID-19 on Daily Life. Psychiatry Research, 289(April), 113098. https://doi.org/10.1016/j. psychres.2020.113098

UNICEF España. (2020) Salud mental e infancia en el escenario de la COVID-19. UNICEF España. https://www.unicef.es/sites/unicef.es/ files/comunicacion/COVID19_UNICEF_Salud_Mental.pdf

Zhao, J., Chen, C., y Zhao, L. (2020). The spread characteristics of music videos relating to COVID- 19 in China online video platforms. International Journal of Communication and Society, 2(1), 1-11.

\section{CV}

Priscila Alvarez-Cueva. Es estudiante de doctorado en el Departamento de Comunicación de la Universidad Pompeu Fabra en Barcelona, Cataluña, España. Actualmente está trabajando en su tesis doctoral sobre música comercial y su papel en la construcción de identidades entre adolescentes y adultos jóvenes, en España y Ecuador. Tiene una licenciatura en comunicación social y publicidad de la Universidad del Azuay (Cuenca, Ecuador), y una maestría en estudios internacionales, medios, poder y diferencia de la Universidad Pompeu Fabra. Fue Coordinadora del área de comunicaciones de la Red Nacional de Investigación y Educación del Ecuador (CEDIA), durante dos años. Ha realizado varios talleres de capacitación sobre masculinidades, feminidades, roles de género y mitos románticos en los medios, con un enfoque principal en la música. En 2020, realizó una visita de investigación en la Universidad de Porto.

Maria-Jose Masanet. Es Profesora Lectora Serra Húnter en el Departamento de Biblioteconomía, Documentación y Comunicación Audiovisual de la Universitat de Barcelona. Ha sido investigadora y profesora en la Universitat Pompeu Fabra (2010-19) y profesora visitante en la Loughborough University, la Université Sorbonne Nouvelle, la Universidad Central de Venezuela y la Ghent University. Es miembro del grupo de investigación DHiGeCs (UB) y del centro de estudios CRICC (UB). Ha participado como investigadora y project manager en los proyectos europeos TRANSMEDIA LITERACY (H2020) y TRANSGANG (ERC-Advanced Grant). Sus líneas de investigación se centran en la educación mediática, las narrativas transmedia, la adolescencia y juventud, las series de televisión y el género. Ha publicado su trabajo en diferentes revistas científicas como New Media \& Society, Information, Communication \& Society, Learning, Media \& Technology o Journal of Youth Studies, entre otras.

Ana Belén Cano-Hila. Es Profesora Lectora Serra Hunter en el Departamento de Sociología, de la Universidad de Barcelona, donde enseña sociología urbana, sociología del medio ambiente, educación urbana y comunitaria. Es doctora en Sociología y miembro del grupo de investigación CRIT (UB). Sus principales intereses de investigación son la exclusión social, las desigualdades urbanas, participación ciudadana, transformación social, juventud y barrios. Ha realizado estancias de investigación en la Università degli Studi Milano-Bicocca, Universidade Nova de Lisboa y Fakultet for Samfunnsfag, Høgskolen i Oslo og Akershus. Actualmente, es miembro del RC21 of Urban and Regional Development of the ISA y del Comité de Estudios de Juventud de la Federación Española de Sociología. 